\title{
POLÍTICAS GOVERNAMENTAIS E TRANSFERÊNCIAS FEDERAIS DE RECURSOS FINANCEIROS NO TERRITÓRIO GOIANO
}

\section{Government Policies and Transfer of Federal Funding in Territory of Goias}

Prof $^{\circ}$ Tadeu Alencar Arrais

Universidade Federal de Goiás IESA-UFG, Campus Samambaia, Prédio do IESA/IQ2, CEP: 74001-970 Goiânia (GO), Brasil Tel/Fax: (+ 55 62) $35211170 / 35211184$ - tadeuarrais@ibest.com.br

\section{$a_{a} \boldsymbol{a} a a$}

\begin{abstract}
Resumo
O artigo discute as políticas governamentais tendo como foco as transferências de recursos do governo federal. Partimos do princípio que as transferências de recursos constituem importante elemento para a análise das transformações territoriais, o que coloca no centro da discussão a função do Estado. Para demonstrar esse Municípios), do FUNDEB (Fundo de Desenvolvimento da Educação Básica), da Previdência Social e do Bolsa Família, relacionando os resultados com o perfil demográfico e a dinâmica econômica regional do território goiano. No final, elencamos alguns argumentos sobre os impactos desse tipo de política governamental na produção do território, com o propósito de sugerir uma agenda de pesquisa para a geografia.
\end{abstract}

Palavras chave: Política governamental; transferências de recursos; território goiano.

\begin{abstract}
The article discusses government policies focusing on resources transfer from federal government. We assume the transfers of resources are the important element for the analysis of territorial transformations, which puts in the center of discussion the role of the state. To demonstrate this argument we described, in the municipal scale, resources from the FPM (Municipal Participation Fund), the FUNDEB (Fund for Development of Basic Education), Social Security and Family Allowance, the results relating to the demographic profile and regional economic dynamic of Goias territory. In the end, casts some arguments about the impact of this type of government policy in the production of the territory, in order to suggest a research agenda for the geography.
\end{abstract}

Keywords: Government policy, resource transfers, Goias territory

\begin{abstract}
Resumen
El artículo analisa las políticas del gobierno que se centra en las transferências de recursos Del gobierno federal. Suponemos que las transferências de recursos son um elemento importante para el análisis de las transformaciones territoriales, lo que pone em el centro de la discusón el papel del Estado. Para demonstrar este argumento, se describe, en la escala municipal, los recursos del FPM (fondo de Participación Municipal) el FUNDEB (Fondo Para el Desarrollo de La Educación Básica), Seguridad Social y Asignaciones Familiares. Los resultados em relación com el perfil demográfico y dinâmica económica regional del território de Goiás. Al final, se arroja algunos de los argumentos acerca de los impactos de este tipo de política gubernamental em la producción del território, a fin de proponer uma agenda de investigación para la Geografía.
\end{abstract}

Palavras clave: política gubernamental, la transferências de recursos, el território de Goiás.

\section{aaCaa}




\section{INTRODUÇÃO}

A crença no progresso espontâneo pode cegar-nos quanto ao papel do governo na vida econômica. Este papel consiste, muitas vezes, em alterar o ritmo da mudança, apressando-o ou diminuindo-o, conforme o caso. Se acreditarmos que tal ritmo é inalterável ou, o que é pior, se acreditarmos ser um sacrilégio intervir com ele, então não existe mesmo um campo para qualquer intervenção.

Karl Polanyi, A grande transformação, p. 55.

Entre a miríade de atores sociais (governos, movimentos sociais, sociedade civil organizada, sindicatos, corporações, mídia, empresas etc.) que produzem o território, poucos duvidariam sobre o protagonismo do Estado, na medida em que ele é responsável pela dotação de infraestrutura, regulamentação jurídica, financiamento da produção, centralização e repartição de recursos provenientes de impostos, além de constituir um contínuo palco de disputas pelo atendimento de diferentes demandas sociais. Um ator social, conforme Markusen (2005), é um agende decisório. Portanto, sua ação, em diferentes escalas, transforma o território. O Estado, como ator centralizador do poder político, para lembrar Castro (2005), será determinante em nossa análise. Seguindo a acepção de Raffestin (1993), Estado é o principal ator sintagmático na produção do território. E produção refere-se ao conjunto material (infraestrutura de circulação e produção, por exemplo), à regulação jurídica (conjunto de leis que ordenam a produção do território e as relações entre os diferentes atores), assim como ao conteúdo simbólico.

Na perspectiva analítica adotada, tanto a noção jurídico-política de território, quanto a econômica, da forma analisada por Haesbaert (2004), encontram-se imbricadas, o que justifica a centralidade de um tipo de ação governamental (transferência de recursos) em nossa análise. O território que está em discussão é um recorte do território nacional. Trata-se de um recorte territorial porque compreende limites intranacionais, mas também de um recorte político, pois tratamos de uma forma jurídico-política dotada de certo nível de autonomia na distribuição dos recursos, regulação econômica e atendimento das diversas demandas da sociedade goiana.

Também é importante salientar que as mudanças na própria concepção de Estado, tributárias das mutações políticas e econômicas implicaram, ao longo dos tempos, nas discussões sobre a capacidade de o Estado intervir no território. Diferentemente das matrizes do Wefare state, as visões liberais, dentre as quais se pode incluir aquelas práticas defendidas por Ohmae (1996), tem relação direta com a forma de produção do território, afinal os programas de privatização, de desregulamentação e de ajuste fiscal, em diferentes contextos espaciais, implicaram diretamente na forma de intervenção no território. Boron (1994, p.199) resume essas questões na América Latina da seguinte forma:

A discussão sobre a crise do Estado assistencialista tem que ser enquadrada à luz destes parâmetros porque, em caso contrário, se reduziria a uma simples contraposição abstrata de preferências doutrinárias que pouco tem a ver com a realidade efetiva das coisas. A ofensiva neoliberal prescinde desses dados e se apóia em uma visão profundamente ideologizada do funcionamento do capitalismo que ignora o papel central que o Estado joga no processo de acumulação. Sua retórica antiestatista não se compatibiliza com a maciça presença do gasto público e as sutis, mas penetrantes formas de intervenção estatal que caracterizaram desde sempre o funcionamento dos capitalismos realmente existentes.

Na verdade, a forma de atuação do Estado só pode ser compreendida a partir de seu conceito e de sua função em sociedade capitalista. A divergência não se origina apenas no campo da prática, mas, sobretudo, no campo das idéias. A ironia de Offe (1991) em relação à função do Estado na sociedade capitalista ilustra esse fato:

O desagradável segredo do Estado social reside em que, apesar do seu efeito sobre a acumulação capitalista poder muito bem tornar-se destrutivo (como a análise conservadora demonstra tão enfaticamente), a 
sua eliminação seria evidentemente diruptiva (fato que a crítica conservadora sistematicamente ignora). A contradição consiste em que o capitalismo não pode coexistir com o Estado social nem continuar existindo sem ele. (OFFE, 1991, p. 122)

Em um estudo sobre a história do neoliberalismo, Harvey (2008) cita quatro características daquilo que qualifica de acumulação por espoliação. São elas: 1) privatização e mercadificação; 2. Financialização. 3. Administração e manipulação de crises. 4. Redistribuição via Estado. Em relação a essa última, o autor coloca:

O Estado, uma vez neoliberalizado, passa a ser o principal agente de políticas redistribuitivas, revertendo o fluxo que vai das classes altas para as baixas, presente na era do liberalismo embutido. Ele o faz antes de tudo promovendo esquemas de privatização e cortes de gastos públicos que sustentam o salário social. (HARVEY, 2008, p. 176).

Ao longo do século XX assistimos diferentes formas de intervenção no território. As políticas econômicas para industrialização e o planejamento econômico e regional para lidar com a desigualdade regional, empecilho para a acumulação do capital, configuraram em algumas dessas práticas. Entretanto, mesmos essas práticas, foram condenadas a partir da década de 1980, pois lembravam o intervencionismo, sempre condenado pelo liberalismo. O fato é que o Estado moderno sempre foi caracterizado como uma arena de disputas das diferentes demandas sociais e não há porque negar, portanto, a existência de disputa entre atores sociais pelo poder político instituído no Estado. Nesse ambiente de disputas, quase sempre, esta em jogo a noção de que determinados grupos de atores sociais tem mais ou menos atenção do Estado em termos de políticas governamentais. É assim que parcela do mercado, representado por corporações ligadas ao setor de telecomunicações e energia, viram com bons olhos o processo de desregulamentação e privatização e criticam, ao mesmo tempo, as políticas de transferências de renda. Esta aí a natureza do Estado. Para além de uma força institucional burocratizada e organizada para sustentar a ditadura de classe, para fazer referência a pertinente crítica de Poulantzas (1985), o Estado está mais próximo de uma arena institucional aberta aos processos históricos e políticos, sem que isso signifique que ele não seja um ambiente de disputas para a efetivação de projetos hegemônicos.

\section{POLÍTICA GOVERNAMENTAL E PRODUÇÃO DO TERRITÓRIO}

As ações do Estado sobre o território não ocorrem no vazio, seja porque o território é composto por uma miríade de atores sociais com diferentes naturezas políticas, seja porque o território está distante de constituir-se de uma planície isotrópica, especialmente em um país como o Brasil, onde desigualdade e pobreza caminham juntas, tornando o território palco constante de disputas.

Partimos do princípio que a ação no território é intencional. Isso significa que a ação traduz um projeto político. É uma projeção, expressa na paisagem territorial, do quadro de interesses do Estado em convergência com outros atores sociais em relações de poder, sempre, assimétricas. A esse conjunto de ações (políticas, econômicas e sociais) ordenadas no território denominaremos, genericamente, de política governamental. Nesse sentido se pode falar tanto em planejamento econômico ou mesmo no planejamento governamental através das diversas modalidades, setores e escalas. A opção pelo termo política governamental, em detrimento do termo política pública, resulta de uma noção de que o conceito de política já tem uma natureza pública, por ser, sobretudo, uma relação e ocorrer, como lembrou Arendt (2002), no entre os homens. Política, como relação entre atores, só existe no âmbito público. Quanto ao adjetivo governamental, acreditamos que serve melhor aos nossos propósitos que o estatal. Se fossemos recorrer às definições clássicas de clima e tempo, diríamos que o primeiro (estatal) corresponde ao Estado, pois se trata de um conceito de fundo, estrutural e o segundo (governamental) ao tempo, uma vez que é possível, mesmo nos marcos da 
sociedade capitalista, variações na ação governamental, em função de agendas partidárias próprias do jogo da democracia representativa. Ademais, política governamental tem o mérito de colocar em evidência o protagonismo dos diferentes governos para atender as demandas do conjunto da sociedade e assim interferir na produção do território. Política governamental refere-se às escalas e também ao conjunto de ações realizadas entre os entes federativos. Mesmo que o poder de ação dos governos municipais seja menor que o dos governos estaduais e federal, sua permeabilidade, na medida em que não é apenas um recorte administrativo, o coloca como ator importante no cenário político brasileiro.

Para compreensão da política governamental também é fundamental considerar o sistema federativo e as conjunturas econômicas e políticas, afinal, em um mundo integrado economicamente, as demandas dos diversos atores sociais podem ser influenciadas pelo movimento do câmbio, pelas decisões econômicas ou mesmo pelo quadro das decisões e agendas político partidárias. Quando tratamos, no caso do Brasil, de políticas governamentais com impactos nos estados da federação, também devemos levar em consideração a equação entre a autonomia dos Estados e municípios à luz das transformações institucionais, especialmente a partir da Constituição Federal de 1988. Assim é que mudanças em alíquotas de impostos, como a redução do IPI (Imposto sobre Produtos Industrializados) afetam os repasses de recursos, a exemplo do FPM, mas privilegiam os atores vinculados à indústria de transformação, especialmente de bens duráveis. Ademais, considerando a escala municipal, as políticas governamentais podem partir ou mesmo serem implementadas em conjunto com os governos federal e/ou estadual, como os consórcios intermunicipais ou mesmo a participação dos municípios na gestão de programas de transferência de renda, a exemplo do Bolsa Família. A rigor, apesar de ser um truísmo, toda política governamental é territorializada nos municípios. Na análise da produção do território, as transferências federais para os governos municipais e para os cidadãos adquirem importância na análise territorial por:

- influírem na solvência dos governos municipais, especialmente no caso das transferências diretas.

- comporem, no caso das transferências diretas para o cidadão, a renda principal ou mesmo uma complementação indispensável para a população mais pobre.

- serem funcionais para o mercado, com impacto no varejo e na geração de empregos na escala municipal e regional.

Os três pontos são suficientes para justificar a importância desse tipo de política governamental na produção do território, o que demonstraremos a partir da análise e espacialização dos recursos na escala municipal.

\section{IMPACTOS DAS POLÍTICAS GOVERNAMENTAIS NA ESCALA MUNICIPAL}

A política de centralização e repasses de recursos para estados e municípios é tema recorrente no debate político brasileiro. As três esferas de governo (Federal, Estadual e Municipal), com justificativas semelhantes, reclamam sobre a defasagem de recursos para atender suas demandas. Os governos municipais, representados por associações como a CNM (Confederação Nacional dos Municípios), argumentam que os problemas brasileiros ocorrem na escala municipal e, portanto, a divisão de recursos deveria ser mais equitativa. Os governos estaduais, com argumentos semelhantes, reclamam das dificuldades em saldar o funcionalismo e atender as demandas de saúde, educação e segurança, entre outras. Ao analisarem essa situação, Gasparine \& Miranda (2006, p.7), colocam:

A questão é que a atribuição das responsabilidades não necessariamente se ajusta à distribuição específica das bases tributárias. Pelo contrário, a coincidência entre ambas é rara. Surge então a primeira das razões 
para a criação das transferências: adequação entre capacidade arrecadatória e necessidade dos gastos públicos diante das suas melhores distribuições entre as esferas de governo. Em outras palavras, a falta de coincidência entre atribuições e arrecadação, em cada nível de governo, faz surgir desequilíbrios verticais cuja superação se dá por meio das transferências.

Esse debate, para além de uma perspectiva fiscal, envolve a própria cultura política localista brasileira e camufla, em muitos casos, problemas crônicos em relação ao uso, geração e repartição de recursos financeiros pelos entes federativos. De certa forma também se inscreve no tema do federalismo fiscal. No entanto, não é nosso objetivo discutir essa perspectiva. O propósito é demonstrar, a partir do mapeamento das transferências do governo federal, descritas na figura 01, como os recursos governamentais interferem na produção dos territórios, tendo como foco de análise a escala municipal. Para tanto, dividimos as transferências federais de recursos selecionadas em dois conjuntos: a) transferências diretas para os municípios; b) transferências diretas para o cidadão. A espacialização desse conjunto de transferências oferecerá uma imagem do território goiano a partir da presença do Estado, demonstrando que sua presença no território não se restringe à distribuição de infraestrutura, financiamento da produção ou mesmo regulação jurídica.

Quadro 1 - Principais Transferências Federais Diretas

\begin{tabular}{|c|c|c|c|}
\hline \multicolumn{2}{|c|}{ Município* } & \multicolumn{2}{c|}{ Cidadão } \\
\hline FPM & FUNDEB & Bolsa & Previdência \\
Fumília & Social \\
Municípios & Fundo Nacional de & & \\
& $\begin{array}{c}\text { Desenvolvimento da Educação } \\
\text { Básica }\end{array}$ & & \\
\hline
\end{tabular}

*Outras transferências constitucionais federais para os municípios são a CIDE (Contribuição de Intervenção no Domínio Econômico), o ITR (Imposto Territorial Rural) e o FEX (Fundo de Apoio às Exportações), além de convênios em diversas áreas e obras resultantes de verbas de bancada, entre outras.

É inegável a centralidade dos recursos na escala federal, muito embora isso não configure, fundamentalmente, em um problema. Apenas as transferências constitucionais do governo federal para o governo do Estado de Goiás, em 2010, somaram R\$2.516.340.853,25. Diretamente para os 246 governos municipais foram repassados, em 2010, o total de R \$ 2.845.016,291,00 (Tesouro Nacional, 2011). Esse valor é maior que o total do ICMS (Imposto Sobre Circulação de Mercadorias e Serviços) repassado pelo Estado aos governos municipais. Quando observamos as receitas globais, notamos, especialmente nos municípios abaixo de 20.000 habitantes, a dependência das transferências do governo federal, especialmente o FPM (Fundo de Participação dos Municípios) e do Governo Estadual, como a parcela do ICMS (Imposto Circulação de Mercadorias e Serviços). Mas as finanças municipais ainda são compostas por transferências resultantes de convênios, a exemplo do SUS (Sistema Único de Saúde), além das receitas tributárias, dentre as quais as mais importantes são os impostos sobre propriedade, transferência de bens imóveis e serviços de qualquer natureza. Como demonstramos em outro momento (Arrais, 2008), há uma tendência de as receitas tributárias próprias diminuírem na proporção que a população decresce, já que essas exigem, entre outras questões, certo grau de amadurecimento da burocracia administrativa para cobrança de impostos e taxas, entre outros fatores levantados por Abrucio \& Couto (1996).

a) Transferências diretas para os municípios

As principais transferências constitucionais da União para os muni $\neg$ cípios goianos são o FPM (Fundo de Participação dos Municípios) e o FUN $\neg$ DEB (Fundo de Manutenção e Desenvolvimento da Educação Básica e de Valorização da Educação). Em comum entre as duas trans- 
ferências obser $\neg$ vamos o componente populacional. O FPM utiliza como critério o tamanho da população. A população de cada município é enquadrada em uma cota populacional e a partir de um índice pré-determinado é calculado o coeficiente de distri $\neg$ buição de recursos. Já o FUNDEB é baseado no número de matrículas no ensino básico, registrado a partir de informações do Censo Escolar.

O FPM é caracterizado como uma transferência de caráter distributivo, uma vez que todos os municípios brasileiros recebem os repasses. Em 2009 foram repassados para os governos municipais goianos o total de $\mathrm{R} \$ 1.448 .491 .389,39$, valor que passou para $\mathrm{R} \$ 1.572 .006 .655,00 \mathrm{em} 2010$. $\mathrm{O}$ menor valor repassado em 2010, correspondente à primeira cota, foi $\mathrm{R} \$ 3.600 .677,06$ e o maior de $R \$ 128.784 .724,34$. A figura 1 demonstra um padrão disperso de distribuição, uma vez que em todas as regiões do território goiano há municípios com população abaixo de 10.000 habitantes, estando a faixas acima de 50.000 concentradas na Região Metropolitana de Goiânia e no Entorno do Distrito Federal, exceção para os municípios de Jataí, Rio Verde, Itumbiara e Catalão. Dos 246 municípios goianos, 161 se enquadraram na menor faixa de repasse. Entretanto, esses municípios não são homogêneos, havendo uma grande variação em termos populacionais na mesma faixa. São 44 abaixo de 2.000 habitantes e 82 entre 2000 e 5.000. Observa-se que a concentração das primeiras faixas, em termos regionais, esta no Norte Goiano, Nordeste Goiano e Oeste Goiano. Considerando as demandas municipais, é fácil supor as diferenças em termos de atendimento de demandas na área de saúde, educação e infraestrutura urbana de um município abaixo de 2.000 habitantes e de outro de 9.000 habitantes.

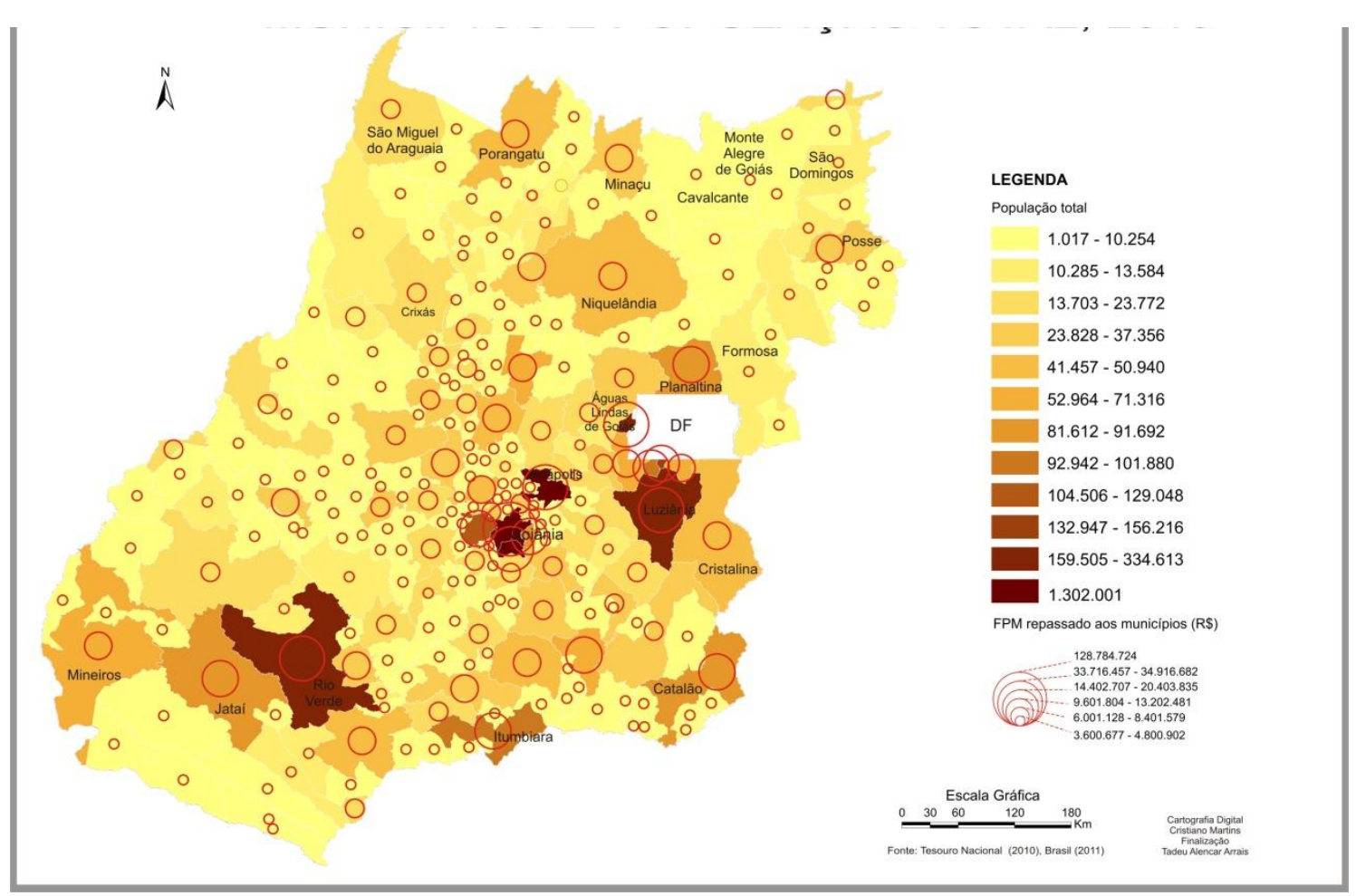

Figura 1- Fundo de Participação dos municipios e participaçãoi total Fonte: Tesouro Nacional (2010); Brasil (2011)

Nos municípios menos populosos registra-se a tendência de maior participação dos FPM no total das receitas tributárias municipais. Veja-se, por exemplo, que em Catalão, Rio Verde e Aparecida de Goiânia a participação do FPM no total das receitas do executivo foi menor. Contribui 
para isso, o perfil das atividades econômicas, com participação da indústria de transformação, a agropecuária e o setor de serviços, o que reverbera no uso do solo e, portanto, nos impostos sobre propriedade, assim como no ISSQN (Imposto Sobre Serviços de Qualquer Natureza).

Quando consideramos a variação per capita entre as faixas verificamos o maior representação nos municípios de menor população. Em Cachoeira Dourada, por exemplo, o valor per capita do FPM, em 2010, foi de R \$ 2.241,00, em Itajá R\$ 711,31, em Ipameri R \$ 339,66 e em Aparecida de Goiânia R\$ 76,62. Muito embora os dados devam ser considerados à luz da diversificação das economias municipais e regionais, a figura 02 indica o caráter pulverizado do FPM.

Tabela 1 - Participação do FPM nas Receitas Municipais, Municípios Goianos Selecionados

\begin{tabular}{|c|c|c|c|c|}
\hline MUNICÍPIO & $\begin{array}{c}\text { POPULAÇÃO - } \\
2010\end{array}$ & $\begin{array}{l}\text { Total de receitas do } \\
\text { executivo }\end{array}$ & Total do FPM & $\begin{array}{c}\text { \% do FPM em relação } \\
\text { ao total de receitas do } \\
\text { executivo }\end{array}$ \\
\hline Cachoeira de Goiás & 1.417 & $5.458 .781,99$ & $3.600 .677,06$ & 65,96 \\
\hline Avelinópois & 2.450 & $6.502 .807,99$ & $3.600 .677,06$ & 55,37 \\
\hline Baliza & 3.714 & $7.325 .928,46$ & $3.600 .677,06$ & 49,14 \\
\hline Itajá & 5.062 & $10.393 .825,73$ & $3.600 .677,06$ & 34,64 \\
\hline Edéia & 11.260 & $19.982 .313,27$ & $4.800 .902,63$ & 24,02 \\
\hline São Domingos & 11.272 & $8.143 .192,20$ & $3.600 .677,06$ & 44,21 \\
\hline Crixás & 15.760 & $28.539 .874,92$ & $6.001 .128,26$ & 21,02 \\
\hline Ipameri & 24.735 & $31.407 .742,60$ & $8.401 .579,44$ & 26,75 \\
\hline Posse & 31.419 & $32.520 .241,81$ & $9.601 .849,94$ & 29,52 \\
\hline Catalão & 86.647 & $146.056 .943,59$ & $15.602 .932,91$ & 10,68 \\
\hline Novo Gama & 95.018 & $64.042 .310,30$ & $16.803 .158,48$ & 26,23 \\
\hline Rio Verde & 176.424 & $241.814 .187,17$ & $34.916 .682,83$ & 14,43 \\
\hline Aparecida de Goiânia & 455.657 & $223.413 .971,69$ & $34.916 .682,83$ & 15,62 \\
\hline
\end{tabular}

Fonte: Brasil (2011), Tesouro Nacional (2011), TCM-GO (2011)

O padrão de distribuição do FUNDEB segue a oferta da infraestrutura na área ensino, com foco na educação infantil e no ensino fundamental. $O$ valor total repassado para os municípios em 2010 foi de R \$ 1.500.865.275,78, menor que o FPM, que foi de R\$1.572.006.655,00. O FUNDEB destina-se às ações de complementação salarial e manutenção e desenvolvimento, na proporção de $60 \%$ do total para a primeira ação e $40 \%$ para a segunda ação. A maior parte dos recursos encontra-se concentrada na Região Metropolitana de Goiânia e no Entorno do Distrito Federal. É nessas regiões que a contabilidade do FUNDEB é mais difícil, já que existe intensa mobilidade para estudos, pois Goiânia e também do Distrito Federal oferecem melhor infraestrutura de serviços educacionais. A mobilidade intermunicipal é menos freqüente nos municípios das demais regiões, exceto para aqueles polarizados por cidades médias. Esse tipo de procedimento, que aproveita da infraestrutura de outros municípios, foi caracterizado por Machado (2009) como free rider

Dos 246 municípios goianos, 153 receberam recursos acima de $\mathrm{R} \$ 1.000,000,00$. O valor médio das transferências pode variar a partir das etapas, modalidades e tipo de estabelecimentos educacionais, como descrito na lei número 11.494, de 20 de junho de 2007, que regulamenta o FUNDEB. Por exemplo, o valor per capita destinado às escolas de tempo integral são maiores que aqueles destinados às escolas de apenas um turno. Em Abadia de Goiás, na Região Metropolitana de Goiânia, o valor médio por aluno no ano de 2010 foi de R\$ 1.762,04 e em Rio Verde, no Sudoeste Goiano, o valor médio foi de $\mathrm{R} \$ 1.732,67$. O fato é que FUNDEB é responsável pelo atendimento das demandas municipais e adquiriu importância ímpar nas gestões municipais. De 
certa forma o FUNDEB também possibilitou maior autonomia para determinados grupos de atores sociais. Para citar um exemplo, professores do município de Itapirapuã, por intermédio do sindicato SINDAPUÃ (Sindicato dos Servidores Públicos Municipais do Itapirapuã-GO), por meio de ofício enviado à Prefeitura Municipal de Itapirapuã, no dia 16 de agosto de 2011, cobraram providências em relação aos atrasos no salário, tendo como justificativa o conhecimento do valor repassado do FUNDEB ao município. Esse tipo de reivindicação tem sido comum nas diversas regiões do país, e é um indicativo dos efeitos de uma política governamental nas relações entre os atores sociais.

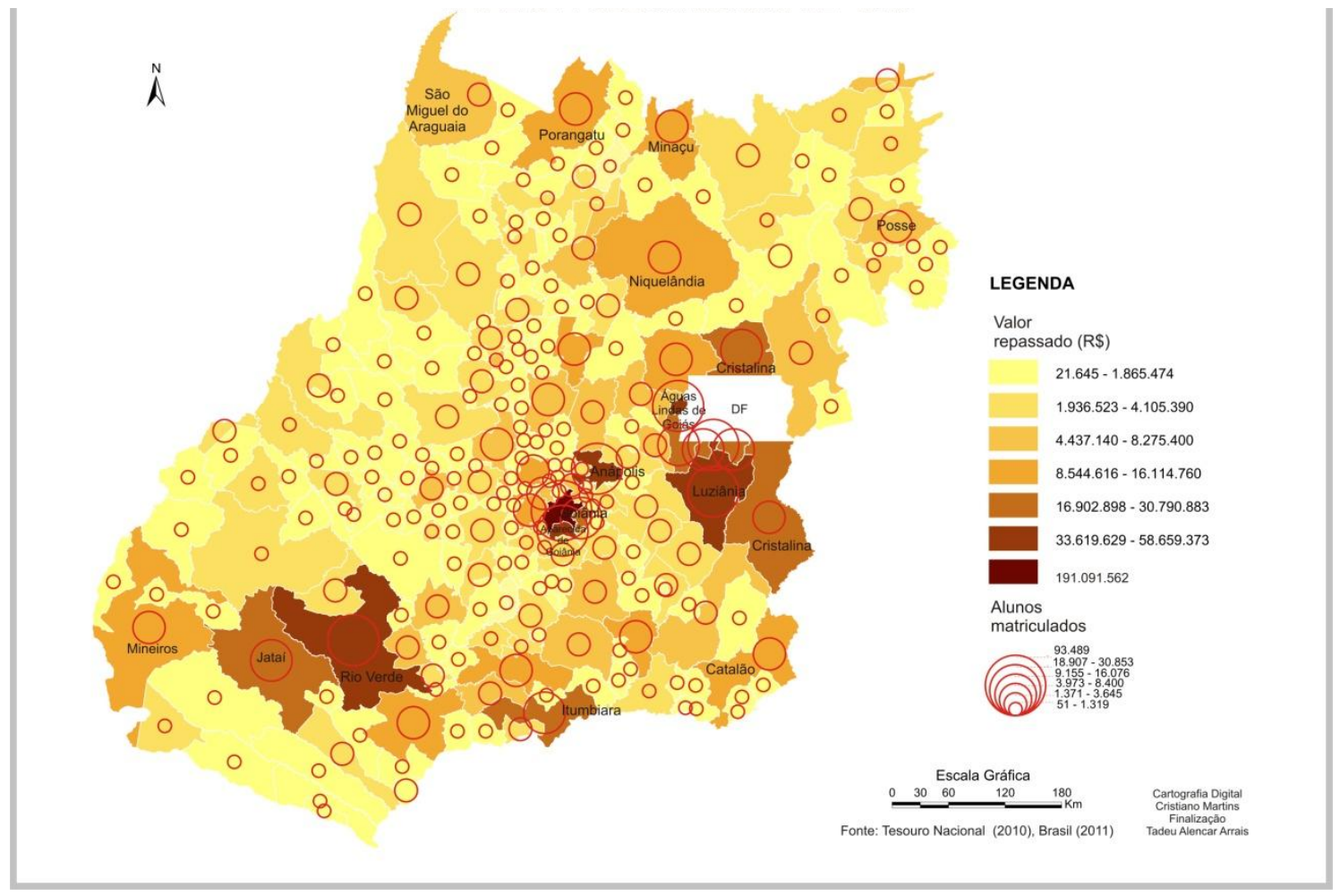

Figura 2 - Valor Repassado do FUNDEB e alunos matriculados na rede Publica Municipal - 2010 Fonte:Tesouro Nacional (2010); Brasil (2011)

\section{b) Transferências diretas para o cidadão}

Em Goiás, segundo dados do Censo Demográfico 2010, 215.975 pessoas residiam em domicílios permanentes sem rendimento ou com renda domiciliar per capita com rendimento entre 1 e 70 reais (BRASIL, 2011b). Diante desses dados e para além do debate sobre o aspecto ideológico de programas de transferência de renda, é notória sua importância para a capitalização de um território com predomínio de municípios pouco populosos e pouco diversificados economicamente. O mesmo raciocínio pode ser empregado para a Previdência Social, uma vez que o benefício é transferido direto para o cidadão.

Em Goiás, no ano de 2010, o valor total de beneficiários da Previdência Social foi de R \$ 4.931.958.279,00. Desse total, R\$ 1.371.072.922,00 destinou-se à Previdência Rural. O valor dos benefícios da Previdência Rural é maior, proporcionalmente, nos municípios de menos populosos. Dos 246 municípios goianos, em 2010, em 72 foram registrados repasses acima de 1 milhão de reais e outros 174 abaixo de 1 milhão de reais. 


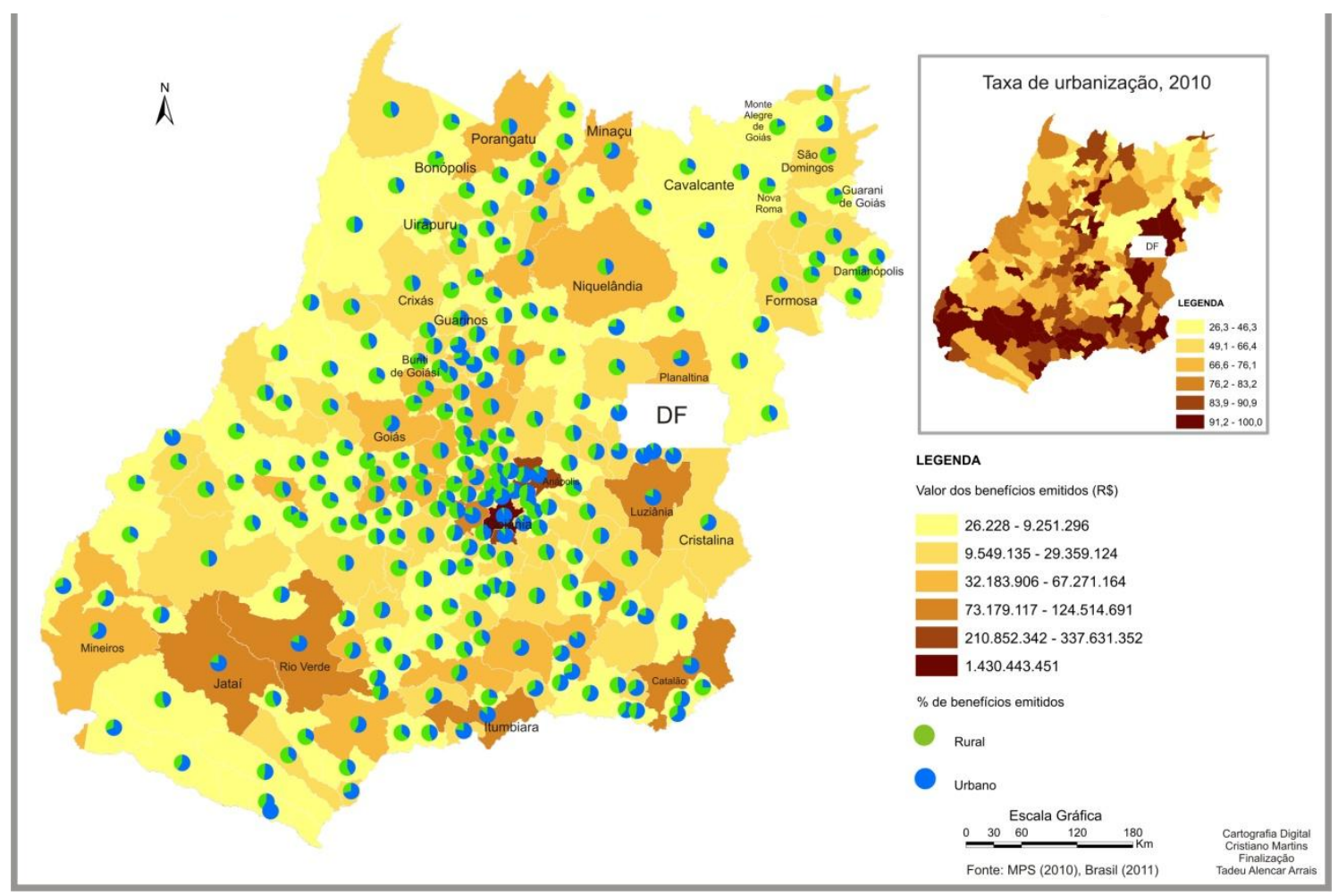

Figura 3 - Benefícios Emitidos pela previdência social - 2010 Fonte: MPS (2010); Brasil (2011)

Muito embora existam no território goiano apenas 22 municípios com população rural maior que urbana, em 2010, 151 municípios tiveram o valor da Previdência Rural maior que a Previdência Urbana. Como pode ser visualizado na figura 3, os municípios com maior participação rural localizam-se na região Norte Goiano e Nordeste Goiano, justamente nas regiões que apresentam maior porcentagem de população rural. Esse fato indica a mobilidade espacial intra-municipal (campo-cidade) dos beneficiários, uma vez que, muito embora ainda possuindo vínculos com a terra, uma parcela significativa de beneficiários residem nas cidades. Além da mobilidade intramunicipal, a literatura destaca para a importância da Previdência Rural para o campo, o que colaborou com o incremento do rendimento domiciliar. Não é incomum, em regiões com predomínio de pequenas e médias propriedades, verificar a presença de até dois beneficiários em uma mesma família, pois a universalização da aposentaria implicou na cessão de benefícios para as mulheres, o que impacta na capitalização das pequenas propriedades e também nas relações de gênero. Considerando o valor do salário mínimo em 2010 ( $\mathrm{R}$ \$ 510,00), a injeção de renda em um domicílio com dois aposentados chegou à $\mathrm{R} \$ 13.260,00$ por ano, reverberando no consumo familiar, com efeito cadeia sobre a economia municipal.

A tabela 2 ilustra o argumento sobre a importância da Previdência Rural para os municípios. Considerando os oito municípios com maiores porcentagens da Previdência Rural, os municípios estão, exceção para São Domingos, abaixo de 7.731 habitantes. Dos oito municípios, em cinco, a população rural era maior do que a urbana. Exceção para Buriti de Goiás, os demais estão localizados no Norte Goiano e Nordeste Goiano. O valor global da Previdência Social foi de R\$ 4.931.958.279,00, superior ao total das transferências federais para os municípios goianos, em 2010, que foi de $\mathrm{R} \$ 2.845 .016 .291,00$. Considerando a distribuição regional dos benefícios, observa-se, do ponto de vista absoluto, a concentração na Região Metropolitana de Goiânia e no Entorno do 
Distrito Federal. Nessas regiões o valor da Previdência Urbana é maior tanto do ponto de vista relativo quanto do ponto de vista absoluto.

Tabela 2 - Participação da Previdência Rural em Relação ao total da previdência, Municípios Goianos Selecionados

\begin{tabular}{c|c|c|c|c|c|c|c}
\multirow{2}{*}{ Município } & \multicolumn{4}{|c|}{ População total } & \multicolumn{2}{c|}{ Repasses da Previdência Social } & \multicolumn{2}{c}{$\begin{array}{c}\text { \% do valor do rural } \\
\text { em relação ao total }\end{array}$} \\
\cline { 2 - 8 } & Total & Urbana & Rural & Total & Urbana & Rural & 78,97 \\
\hline Monte Alegre & 7.730 & 3.164 & 4.566 & 4.586 .062 & 964.629 & 3.621 .433 & 79,07 \\
\hline Uirapuru & 2.933 & 1.464 & 1.469 & 178.182 & 37.300 & 140.882 & 79,44 \\
\hline Guarani de Goiás & 4.258 & 1.763 & 2.495 & 2.215 .820 & 455.573 & 1.760 .247 & 79,95 \\
\hline São Domingos & 11.272 & 5.774 & 5.948 & 9.549 .135 & 1.914 .435 & 7.634 .700 & 80,97 \\
\hline Guarinos & 2.299 & 1.131 & 1.168 & 353.682 & 67.320 & 286.362 & 80,97 \\
\hline Bonópolis & 7.536 & 7.021 & 515 & 97.265 & 18.508 & 78.757 & 82,35 \\
\hline Damianópolis & 3.292 & 1.853 & 1.439 & 934.472 & 164.926 & 769.545 & 83,59
\end{tabular}

Fonte: Brasil (2011), CGU (2011).

O mapa do Bolsa Família, em certa medida, guarda semelhança com o da Previdência Rural, especialmente porque nos municípios menos populosos a proporção desses benefícios é mais representativo. O programa Bolsa Família é ilustrativo do debate político que envolve uma política governamental. Como é resultado da unificação de outras políticas governamentais, é comum a discussão sobre sua paternidade, o que coloca, freqüentemente, um conteúdo comparativo entre o Governo Fernando Henrique Cardoso (1995-2003) e o Governo de Luiz Inácio Lula da Silva (2003-2010). Esse debate, assim como aquele que versa sobre a reprodutibilidade do clientelismo, como qualificado por Martins (2011), foge aos nossos fins. Entretanto, parece ser inegável o caráter integrativo do programa, na medida em que exige determinadas condicionalidades ligadas ao acionamento de serviços de educação e saúde. Outro dado inegável é que o programa atende a parcela mais pobre da população, com foco nas famílias com renda mensal até R 140 por pessoa, sendo que aquelas que se encontram na faixa de $\mathrm{R} \$ 70$ a R \$140, só participam se forem compostas por crianças e/ou adolescentes, o que amplia bastante o universo de atendimento.

O total do Bolsa Família repassado para Goiás, em 2010, foi de $\mathrm{R} \$ 332.609 .540,00$, maior que os $\mathrm{R} \$ 270.71 .524,00$ registrados em 2009. O número de beneficiários também aumentou de 374.067 para 381.557, fato que fomenta a perspectiva, sempre lembrada, da porta de saída. Em 2011, após reajuste na tabela de valores, o valor mínimo e máximo, a depender da composição familiar, passou a variar de $\mathrm{R} \$ 32,00$ até $\mathrm{R} \$ 242,00$. O pagamento pode ser efetuado nas agências bancárias, postos de atendimento, unidades lotéricas ou mesmo estabelecimento comerciais conveniados. Em termos absolutos, verifica-se uma concentração na Região Metropolitana de Goiânia e no Entorno do Distrito Federal, diferentemente das regiões Norte Goiano, Nordeste Goiano e Oeste Goiano, onde os valores relativos são mais expressivos, o que denuncia a importância desses repasses para essas últimas regiões. 


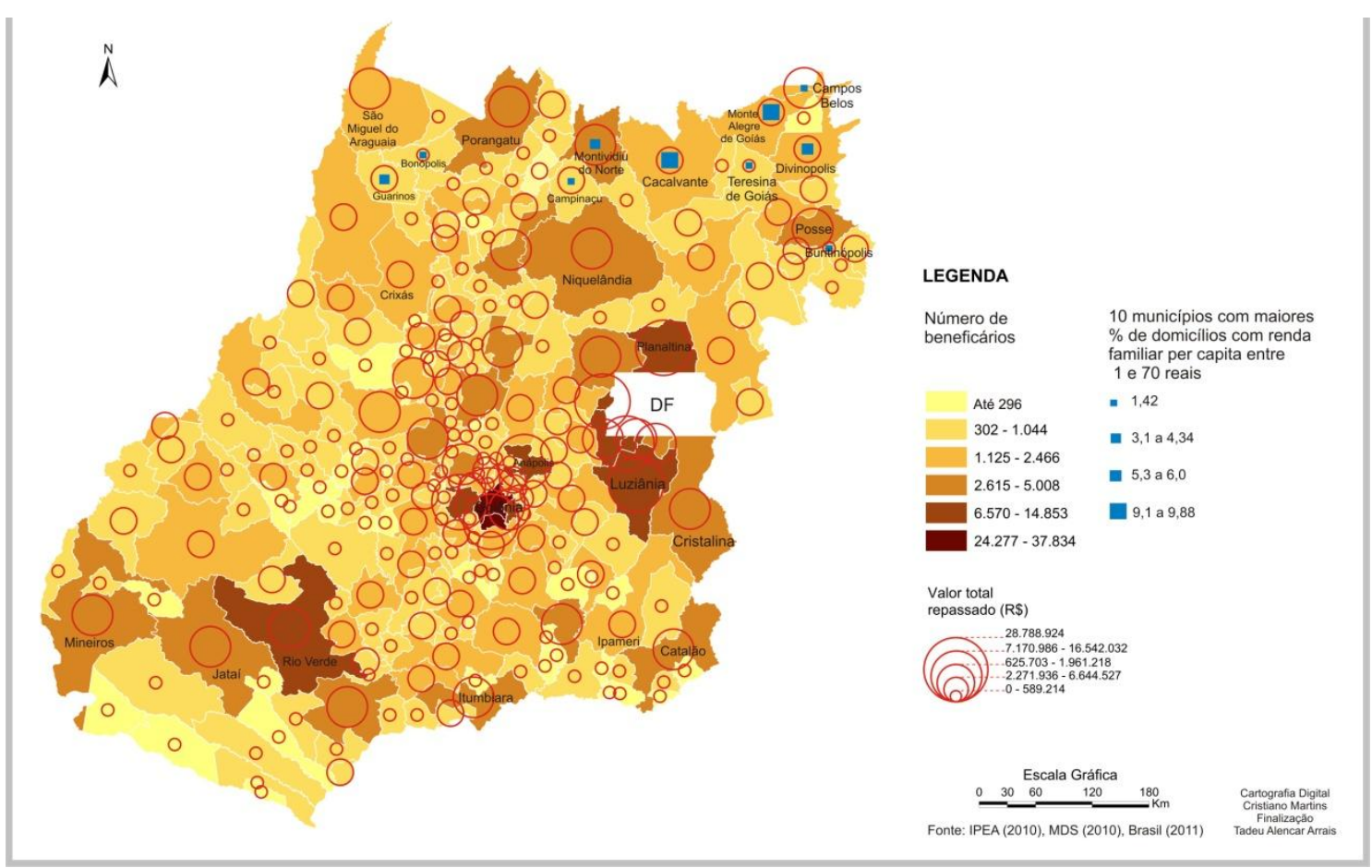

Figura 4 - Família Baneficiadas pelo o Bolsa Família e Valor Total Repassado - 2010 Fonte: IPEA (2010); MDS (2010); Brasil 2011

Dados recentes divulgados pelo IBGE comprovam o foco social do programa. Os 10 municípios com maior proporção de famílias beneficiárias em relação ao total de domicílios, em 2010, possuem população inferior a 9.392 habitantes. As informações na tabela 3 referem-se ao número de famílias beneficiárias e a primeira coluna, após o nome do município, refere-se à porcentagem de famílias beneficiadas em relação ao número total de domicílios dos municípios. Se admitirmos um número médio de 4 pessoas na composição familiar, teremos a noção do total da população atendida pelo Bolsa Família. Quando relacionamos os dados aos municípios com maior número proporcional de famílias em domicílios com renda per capita entre R \$ 1 a R \$ 70 reais, notamos uma correspondência. Dos 1.032 domicílios de Teresina de Goiás, 71, o que corresponde a $6,87 \%$ dos domicílios, estão incluídos na faixa de renda entre $\mathrm{R} \$ 1$ a $\mathrm{R} \$ 70$ reais, o que é significativa, especialmente quando comparamos com a média do estado que é de $1,18 \%$ de domicílios nessa faixa de renda. No município em questão, o menor valor repassado no ano de 2010, por família, foi de $\mathrm{R} \$ 162,00$ e o maior valor foi de $\mathrm{R} \$ 1.326,00$.

Dados recentes divulgados pelo IBGE comprovam o foco social do programa. Os 10 municípios com maior proporção de famílias beneficiárias em relação ao total de domicílios, em 2010, possuem população inferior a 9.392 habitantes. As informações na tabela 3 referem-se ao número de famílias beneficiárias e a primeira coluna, após o nome do município, refere-se à porcentagem de famílias beneficiadas em relação ao número total de domicílios dos municípios. Se admitirmos um número médio de 4 pessoas na composição familiar, teremos a noção do total da população atendida pelo Bolsa Família. Quando relacionamos os dados aos municípios com maior número proporcional de famílias em domicílios com renda per capita entre R\$ 1 a R 70 reais, notamos uma correspondência. Dos 1.032 domicílios de Teresina de Goiás, 71, o que corresponde a 6,87 \% dos domicílios, estão incluídos na faixa de renda entre R\$ 1 a R 70 reais, o que é significativa, especialmente quando comparamos com a média do estado que é de 1,18\% de domicílios nessa faixa de renda. No município em questão, o menor valor repassado no ano de 2010, por família, foi de $\mathrm{R} \$ 162,00$ e o maior valor foi de $\mathrm{R} \$ 1.326,00$.

Raciocínio inverso ocorre naqueles municípios com menor participação do Bolsa Família, registrando participações em relação ao total de domicílio na faixa de renda de $\mathrm{R} \$ 1$ a $\mathrm{R} \$ 70,00$ abaixo de 15,51\%. Em Orizona e Goiânia, por exemplo, 7,14\% e 8,14\% dos domicílios abrigam 
beneficiários do Bolsa Família. Esses municípios, de igual forma, apresentam as menores porcentagens de dados da renda domiciliar entre $\mathrm{R} \$ 1$ e $\mathrm{R} \$ 70,00$ reais.

Tabela 3 - Maiores e Menores porcentagens de municípios de benefícios do bolsa família em relação ao total de Domicilios, Municipios Goianos - 2010

\begin{tabular}{|c|c|c|c|c|c|c|c|c|c|}
\hline \multirow[t]{2}{*}{ Município } & \multirow[t]{2}{*}{$\%$} & \multicolumn{3}{|c|}{$\begin{array}{l}\text { Domicílios particulares com } \\
\text { rendimento nominal mensal } \\
\text { domiciliar per capita de } 1 \text { a } \\
70 \text { reais }\end{array}$} & \multirow[t]{2}{*}{ Município } & \multirow[t]{2}{*}{$\%$} & \multicolumn{3}{|c|}{$\begin{array}{l}\text { Domicílios particulares com } \\
\text { rendimento nominal mensal } \\
\text { domiciliar per capita de } 1 \text { a } \\
70 \text { reais }\end{array}$} \\
\hline & & Total & Urbano & Rural & & & Total & Urbano & Rural \\
\hline Teresina de Goiás & 66,47 & 71 & 32 & 39 & Orizona & 7,14 & 35 & 14 & 21 \\
\hline Campos Verdes & 42,30 & 101 & 92 & 9 & Goiânia & 8,04 & 1373 & 1363 & 10 \\
\hline Montividiu do Norte & 42,04 & 96 & 19 & 77 & Catalão & 10,59 & 137 & 124 & 13 \\
\hline Divinópolis de Goiás & 40,01 & 124 & 73 & 51 & Rio Verde & 10,88 & 296 & 288 & 8 \\
\hline Monte Alegre & 41,62 & 263 & 77 & 186 & Morrinhos & 10,99 & 101 & 88 & 13 \\
\hline Buritinópolis & 39,18 & 96 & 42 & 54 & Jataí & 11,25 & 165 & 141 & 24 \\
\hline Bonópolis & 38,82 & 51 & 15 & 36 & Chapadão do Céu & 11,30 & 2 & 2 & 0 \\
\hline Campinaçu & 36,74 & 23 & 1 & 22 & Bela Vista de Goiás & 13,87 & 70 & 62 & 8 \\
\hline Cavalcante & 36,35 & 421 & 147 & 274 & Buriti Alegre & 12,21 & 28 & 28 & 0 \\
\hline Guarinos & 34,20 & 55 & 28 & 27 & $\begin{array}{l}\text { Aparecida de } \\
\text { Goiânia }\end{array}$ & 15,50 & 760 & 760 & 0 \\
\hline
\end{tabular}

Fonte: Brasil (2011), CGU (2011).

Considerando os repasses para os municípios goianos, 72 tiveram repasses acima de $\mathrm{R} \$$ $1.000 .000,00$ no ano de 2010 e os demais abaixo de R\$1.000.000,00. Muito embora o valor dos repasses esteja concentrado na Região Metropolitana e no Entorno do Distrito Federal, proporcionalmente, são mais relevantes no Nordeste Goiano, Norte Goiano e Oeste Goiano. Sua menor participação proporcional nas áreas mais populosas tem relação direta com as oportunidades de emprego nos diversos setores, especialmente serviços e indústria de transformação, responsáveis pela formalização do emprego e incremento nos rendimentos médios domiciliares.

\section{CONSIDERAÇÕES FINAIS}

As transferências de recursos, compreendidas como políticas governamentais, promovem transformações territoriais. Para que essa perspectiva seja reconhecida, é necessário partir de um conceito de território para além do substrato material e de um entendimento de políticas governamentais para além de ações na área de infraestrutura, políticas macroeconômicas ou mesmo planos setoriais nas diversas áreas. Na verdade, mesmo esse conjunto de ações dependem da solvência dos governos. Se, por um lado, transferências como o FPM e o FUNDEB capitalizam os governos municipais, permitindo a realização das agendas políticas (intervenções urbanísticas, aumento dos salários para o funcionalismo, implementação de rede de assistência social, postos de saúde etc.), por outro lado, as transferências diretas para o cidadão, além de combater a pobreza, podem implicar em maior autonomia para os atores sociais, especialmente em um contexto em que o localismo político é fomentado pela dependência financeira de atores menos privilegiados na escala municipal. Muito embora as transferências diretas avaliadas não representem o total dos recursos transferidos para os governos municipais, ainda assim e a partir dos dados apresentados, podemos sugerir uma agenda de pesquisa que inclua reflexões sobre as seguintes questões:

1. A ideia de uma divisão igualitária, como reivindica o argumento municipalista, não resiste à análise empírica. Imaginar, por exemplo, uma divisão com base no PIB municipal implicaria 
em maior concentração dos repasses como o FPM. O problema é que essa contabilidade não é tão simples. Como mensurar e comparar a relevância dos recursos do FNDE (Fundo Nacional de Desenvolvimento da Educação), os convênios com o SUS (Sistema Único de Saúde), o PSF (Programa de Saúde Familiar) ou mesmo os programas de financiamento para a moradia popular para municípios localizados em diferentes contextos territoriais? Como contabilizar o peso de tais recursos, já que não se originam, exclusivamente, das atividades econômicas e impostos de uma determinada base municipal? Como contabilizar o impacto econômico de uma Instituição Federal de Ensino Superior, cujo financiamento tem sua origem no governo federal, em um município de 50.000 habitantes? Ao que parece, mais que o valor dos recursos, o que esta em jogo é a sua paternidade, o que implica diretamente em distribuição de poder político para a escala municipal. Os recursos permitem ações no território e ação remete, sempre, aos atores que produzem o território.

2. É comum o argumento que o gasto com programas do gênero do Bolsa Família não tenha uma função pedagógica, já que há uma evolução contínua no número de famílias beneficiadas. Em 2008 haviam 245.268 beneficiados pelo Bolsa Família em Goiás, número que passou para 374.067 em 2009 e 381.557 em 2010. O aumento progressivo é compreensível, pois a pobreza e a concentração de renda no Brasil são processos com raízes históricas. Por outro lado, pouco se reclama do valor destinado pelos governos aos programas de incentivos fiscais. Para se ter uma ideia, o valor total de créditos do Produzir, principal programa de incentivos fiscais do governo de Goiás, foi de R 764 milhões (SEPLAN, 2011), superior aos R 332 milhões destinados ao Bolsa Família no território goiano no mesmo ano. Aqui caberia uma pesquisa comparativa sobre a eficácia do Bolsa Família e dos programas de incentivos fiscais na geração de empregos. O primeiro, sem dúvida, é mais pulverizado, especialmente porque os programas de incentivos fiscais tem privilegiado grandes empresas.

3. As transferências analisadas são funcionais para as economias municipais e, portanto, aquecem o mercado. Capitalizar pequenos agricultores, por meio da aposentadoria rural, é incrementar consumo de bens duráveis e insumos agrícolas no comércio local e regional. Capitalizar pobres é ampliar o consumo de bens de consumo não duráveis, impulsionando o varejo local, isso sem contar o impacto positivo resultante das condicionalidades do Bolsa Família.

Pensar as políticas governamentais a partir da ótica das transferências de recursos é pensar, sobretudo, na distribuição do poder para diferentes atores sociais e suas escalas permeáveis. Com anotou convenientemente Lepetit (1998, p.88):

A importância diferente dos recursos de que dispõem os atores e a diversidade da extensão dos campos nos quais eles são suscetíveis de agir estão entre as características essenciais do panorama social e constituem as fontes principais da sua modificação. A variação da escala não é apanágio do pesquisador nem principalmente o produto do processo de construção da pesquisa. É, em primeiro lugar, tarefa dos atores.

Nesse viés interpretativo, a centralidade do Estado é determinante e sua compreensão requer considerar as relações assimétricas de poder entre os atores sociais e, em especial, os atores governamentais. Os dois conjuntos de transferências de recursos atingem e beneficiam grupos específicos de atores sociais que agem e, portanto, produzem um mesmo território. A nosso ver, não se trata mais de comprovar ou não se as transferências, especialmente as diretas como o Bolsa Família e a Previdência Social, produzem efeitos econômicos, mas como e com que intensidade esses efeitos influenciam as relações entre os atores sociais que produzem o território. A questão de fundo refere-se ao fato de que a concepção de Estado tem reflexo direto na forma como os atores produzem o território e daí surgem diferentes políticas governamentais. Nas concepções liberais, as mudanças 
territoriais, bem como as diferenciações territoriais, são propriedade da livre iniciativa. O território, sem contextualização histórica e desprovido de conflitos, seria, ele próprio, senhor do seu destino - um típico liberalismo territorial. Não foi, sequer, produto de uma capitalização diferencial. É por esse motivo que o conceito de Estado é imprescindível nessa discussão. As concepções liberais, como aquelas divulgadas por Hayek (2000), no conhecido Caminhos da servidão, camuflam, em nome da liberdade, o fato de as ações do Estado serem funcionais para o mercado. Camuflam, de igual forma, a perspectiva de mudança, uma vez que a competição é naturalizada como único caminho. Os impactos das políticas governamentais na produção do território podem ser compreendidos a partir desse contexto, já que algumas transferências têm caráter distributivo e outras têm o propósito de distribuir renda. Não se trata de imaginar um Estado neutro, mas de compreender suas funções na sociedade de mercado. Como Offe (1991) alertou, a composição entre arenas de conflitos, processos de luta e distribuição do poder social estão no âmago do conceito de Estado. Falta dizer que essa composição de forças esta expressa na paisagem territorial, tal é o exemplo das políticas governamentais aqui analisadas.

\section{REFERÊNCIAS BIBLIOGRAFICAS}

ABRUCIO, Fernando Luiz; COUTO, Cláudio Gonçalves. A redefinição do papel do Estado no âmbito local. São Paulo em Perspectiva. São Paulo: Fundação Seade, vol. 10, no 3, jul./set. 1996, pp. 40-47.

ARENDT, Hannah. O que é política? Rio de Janeiro: Bertrand Brasil, 2002.

ARRAIS, T.. Diversidade territorial e transferências constitucionais para os municípios: considerações sobre a economia regional goiana. Boletim Goiano de Geografia. Goiânia, 2008.

34 BORON, Atílio A. Estado, capitalismo e democracia na América Latina. Rio de Janeiro: Paz e Terra, 1994. BRASIL. Constituição da República Federativa do Brasil. Brasil, 1988.

BRASIL. Censo Demográfico 2010. Rio de Janeiro: IBGE, 2011.

BRASIL. Lei número 8.212, de 24 de agosto de 1991. In: http://www010.dataprev.gov.br/sislex/paginas/42/1991/8212.htm. Acesso em 28/08/2011.

BRASIL. Lei número 11.494, de 20 de junho de 2007. http://www.planalto.gov.br/ccivil_03/_ato20072010/2007/Lei/L11494.htm. Acesso em 26/08/2011.

CASTRO, Iná Elias de. Geografia e política - território, escalas de ação e instituições. Rio de Janeiro: Bertrand Brasil, 2005.

DAVID, Maurício. Previdência Rural no Brasil: uma análise de seu impacto e eficácia como instrumento de combate à pobreza rural. Seminário FAO/CEPAL/RIMISP. Experiências Exitosas de Combate à Pobreza Rural na América Latina. Agosto/Setembro de 1999. In: http://www.rimisp.org/getdoc.php?docid=1730. Acesso em 16/08/2011.

FREEY, Klaus. Políticas públicas: um debate conceitual e reflexões referentes à prática da análise de políticas públicas no Brasil. Planejamento e Políticas Públicas. N. 212, Junho de 2000.

GASPARINI, Carlos E. \& MIRANDA, Rogério. Evolução dos aspectos legais e dos montantes de transferências realizadas pelo Fundo de Participação dos Municípios. Texto para discussão 1243. Brasília: IPEA, 2006 HAYEK, Friedrich August. O caminho da servidão. 5. ed. Rio de Janeiro: Instituto Liberal, 1990.

HAESBAERT, Rogério. O mito da desterritorialização. Rio de Janeiro: Bertrand Brasil, 2004.

HARVEY, David. A produção capitalista do espaço. São Paulo: Annablume, 2005.

HARVEY, David. O neoliberalismo - história e implicações. São Paulo: Loyola, 2008.

LEPETIT, Bernard. Sobre a escala na história. In: REVEL, Jacques (Org.). Jogos de escalas: a experiência da microanálise. Rio de Janeiro: Editora da FGV, 1998.

MACHADO, Gustavo Gomes. Gestão metropolitana e autonomia municipal: dilemas das transações federativas. Belo Horizonte: Editora PUC MINAS, 2009. 
MARKUSEN, Ann. Mudança econômica regional segundo o enfoque centrado no ator. In: DINIZ, Clério Campolina \& LEMOS, Mauro Borges (Org.). Economia e território. Belo Horizonte: Editora da UFMG, 2005.

MARTINS, José de Souza. A política do Brasil - lúpem e místico. São Paulo: Contexto, 2011.

MENEZES FILHO, Naércio Aquino. Os efeitos do Programa Bolsa Família sobre a economia dos municípios brasileiros. Relatório final de pesquisa. INSPER - Instituto de Ensino e Pesquisa. INSPER, São Paulo, 2009. In.: http://www.ipc-undp.org/publications/mds/33P.pdf. Acesso em 28/07/2011.

Ministério da Fazenda. Secretaria do Tesouro Nacional - STN. Tesouro Nacional. O que você precisa saber sobre as transferências constitucionais relativas aos fundos de participação dos Estados e dos Municípios. Brasília: Tesouro Nacional, 2011.

OFFE, Claus. Trabalho \& sociedade - problemas estruturais e perspectivas para o futuro da sociedade do trabalho. Volume II. Rio de Janeiro: Tempo Brasileiro, 1991.

OHMAE, K. O fim do Estado-Nação. Rio de Janeiro: Campus, 1996.

PEREIRA, José Matias. Finanças públicas: a política orçamentária no Brasil. São Paulo: Atlas, 2009.

POLANYI, Karl. A grande transformação - as origens de nossa época. Rio de Janeiro: Campus, 2000.

POULANTZAS, Nicos. O Estado, o poder, o socialismo. 2a . Ed., Rio de Janeiro: Graal, 1985.

RAFFESTIN, Claude. Por uma geografia do poder. São Paulo: Atica, 1993.

SILVA, Mauro Santos. Teoria do federalismo fiscal: notas sobre as contribuições de Oates, Musgrave, Shah e Ter-Minassia. Nova Economia. Belo Horizonte, janeiro/abril, 2005.

SINGER, André. Raízes sociais e ideológicas do lulismo. Novos Estudos - 85. São Paulo, novembro de 2009. In: http://www.scielo.br/scielo.php?script=sci_serial\&pid=0101-3300\&lng=en\&nrm=iso. Acesso em 16/06/2011.

SOUZA, Celina. Políticas públicas: uma revisão da literatura. Sociologias. Porto Alegre, ano 8, n.16, jul/ dez de 2006. P. 20-45.

Fontes eletrônicas

http://www.tesouro.fazenda.gov.br/estados_municipios/municipios.asp. Acesso entre 10/06/2011 a 15/07/2011.

http://www.seplan.go.gov.br/sepin/. Acesso em 15/08/2011.

http://www.tesouro.fazenda.gov.br/estados_municipios/municipios.asp?UF=GO. Acesso em 19/08/2011.

http://br.transparencia.gov.br/?estado=GO. Acesso em 20/08/2011.

http://www.mpas.gov.br/conteudoDinamico.php?id=423. Acesso entre 15/06/2011 a 25/06/2011.

http://www.seplan.go.gov.br/sepin/pub/serieEB/Port/2trimestre2011/21-tab04.htm. Acesso em 20/06/2011.

http://www.tcm.go.gov.br/site/index.jsf. Acesso em 20/07/2011.

http://www.tesouro.fazenda.gov.br/estados_municipios/download/CartilhaFPEFPM2011.pdf. Acesso em 27/18/2011.

http://nilsonalmir.blogspot.com/2011/08/professores-municipais-de-itapirapua.html. Acesso em 28/08/2011. http://www.cnm.org.br/. Acesso em 18/05/2011.

http://www.mds.gov.br/bolsafamilia. Acesso em 16/07/2011.

Trabalho enviado em agosto de 2011

Trabalho aceito em outubro de 2011 